\title{
Treatment of gastrointestinal autonomic neuropathy
}

\author{
Hans Törnblom ${ }^{1}$
}

Received: 31 October 2015 / Accepted: 5 November 2015 /Published online: 3 December 2015

(C) Springer-Verlag Berlin Heidelberg 2015

\begin{abstract}
The symptoms caused by gastrointestinal autonomic neuropathy in diabetes mellitus is important to highlight since it affects a large proportion of people with diabetes, regardless of whether this is type 1 or type 2 . Gastroparesis and general signs of bowel dysfunction, such as constipation, diarrhoea and abdominal pain are most often encountered and involve both pharmacological and non-pharmacological treatment options. This mini-review summarises a presentation given at the 'Diagnosis and treatment of autonomic diabetic neuropathy in the gut' symposium at the 2015 annual meeting of the EASD. It is accompanied by another mini-review on a topic from this symposium (by Azpiroz and Malagelada, DOI: 10.1007/ s00125-015-3831-1) and a commentary by the Session Chair, Péter Kempler (DOI: 10.1007/s00125-015-3826-y).
\end{abstract}

Keywords Abdominal pain - Autonomic neuropathy · Constipation · Diarrhoea · Gastric electrical stimulation . Gastroparesis

\section{Abbreviations \\ FDA Food and Drug Administration \\ GI Gastrointestinal \\ SIBO Small intestinal bacterial overgrowth}

Hans Törnblom

hans.tornblom@gu.se

1 Department of Internal Medicine and Clinical Nutrition, Institute of Medicine, Sahlgrenska Academy, University of Gothenburg, SE-41345 Gothenburg, Sweden
Gastrointestinal (GI) symptoms are common in the general population. For example, $10-20 \%$ of adults suffer from functional GI disorders [1]. In one of the more meticulously performed epidemiological studies on patients with diabetes mellitus type 1 and type 2, Bytzer et al found that symptoms from all parts of the GI tract were even more common in diabetes, and that GI symptoms of moderate to severe intensity were associated with poorer glycaemic control [2]. All parts of the GI tract might be affected by a GI autonomic neuropathy, but those most commonly encountered are related to stomach and bowel dysfunction.

If an autonomic GI neuropathy is suspected, GI function tests are performed, and studies have suggested that the results of these need to be interpreted with some caution in terms of assessing any potential association between the observed dysfunction and the specific GI symptoms. For example, in one US survey there were no distinct symptom features that would differentiate between a patient with chronic nausea and vomiting with gastroparesis and one with normal gastric emptying [3].

In all the examples of GI autonomic neuropathy below, the mainstay of basic treatment is, as always, the achievement/ maintenance of good glycaemic control.

\section{Gastroparesis}

\section{Dietary treatment}

Dietary treatment represents the fundamental basis of treatment for diabetic gastroparesis, regardless of other therapeutic efforts. The general recommendations are for small, more frequent meals; excess fat and dietary fibre should be avoided and the particle size should be small [4]. The support of a dietitian increases the chances that the diet will have a nutrient 
intake that reaches the daily energy requirements. Indeed, there appears to be a great need for this support since most patients experience difficulties following dietary advice [5]. In general, in terms of symptom-relief, a meal with small particle size seems to be of central importance [6].

\section{Pharmacological treatment}

The recommendations for the medications available for the treatment of gastroparesis were based on the findings of old trials that do not meet the modern, more rigorous standards of evidence [7]. Most of these studies only evaluated the shortterm effects ( $<4$ weeks) of the medications and only included low numbers of patients. Furthermore, it is not certain whether the effects of these treatments on GI symptoms are related to improvements in gastric emptying time [8]. Metoclopramide, one of the more commonly used drugs with dopamine $\mathrm{D}_{2}$-receptor antagonistic effects, has been assessed in four placebo-controlled trials, with effects superior to placebo and with improvement in gastric emptying time [9-12]. Because of the well-known central nervous system side effects, tardive dyskinesia being the most feared, both the US Food and Drug Administration (FDA) and European Medicines Agency recommend that metoclopramide is for short-term use.

An alternative treatment for nausea and vomiting associated with gastroparesis is the dopamine $\mathrm{D}_{2}$-receptor antagonist domperidone. It has shown similar effects but fewer adverse reactions compared with metoclopramide [13]. Erythromycin is a motilin receptor agonist that increases gastric emptying [14] and decreases symptoms, and these improvements are of the same order of magnitude as those observed with metoclopramide [15]. However, erythromycin has the obvious disadvantage of being an antibiotic, as over longer periods its symptom alleviating effects are subject to tachyphylaxia as a result of receptor downregulation. Both domperidone and erythromycin treatment can induce QT interval prolongation, with risk for arrhythmias, and affect the rate of metabolism of other medications through alterations of CYP2D6 (domperidone) and CYP3A4 (erythromycin). Anti-emetics have not been specifically evaluated in gastroparesisassociated nausea and vomiting.

Looking to the future, there are ongoing Phase 2-3 trials investigating motilin receptor agonists without antibiotic effects, ghrelin receptor agonists, serotonin subtype $4\left(5-\mathrm{HT}_{4}\right)$ receptor agonists, an acetylcholine esterase inhibitor and a combined $\mathrm{D}_{2}$ receptor agonist/acetylcholine esterase inhibitor. However, none to date has reached a developmental stage compatible with becoming a prescription drug [16].

\section{Gastric electrical stimulation}

Gastric electrical stimulation (GES) was approved by the FDA as a Humanitarian Device exemption in patients with refractory symptoms of diabetic or idiopathic gastroparesis in 2000 based on the findings of two studies $[17,18]$. This approach produces the best effects on nausea and vomiting in patients with diabetic gastroparesis. A study in which treatment was blinded failed to find a benefit of GES [19]; however, it had positive effects in a long-term clinical follow-up study [20].

\section{Bowel dysfunction}

If the symptoms associated with gastroparesis and the therapeutic options are complicated, the situation is the same when more distal parts of the GI tract are affected by autonomic neuropathy. The overlap between symptom complexes is substantial and in clinical practice the treatment options are more or less the same as for the functional GI disorders. It is very important that the doctor explains to the patient which symptom or symptoms a particular therapeutic measure can improve, so that both patient and doctor have realistic expectations of what can be achieved.

\section{Constipation}

If just looking at relief of constipation as the primary outcome measure, relatively efficient laxative therapy has long been available [21]. If the underlying pathophysiology involves slow-transit constipation, osmotic laxatives are preferred over bulking agents and fibre supplementation. In recent years, prucalopride, an agonist of the $5-\mathrm{HT}_{4}$ receptor has been introduced in clinical practice for the treatment of constipation in women in whom laxatives have not resulted in adequate relief. Three pivotal studies have shown significant effects vs placebo on the key symptom of constipation (i.e. more frequent bowel movements), and have also reported positive effects on quality of life and reassuring safety data [22-24]. Interestingly, other symptoms associated with constipation, such as bloating, discomfort, a sensation of incomplete bowel movement and excessive straining, have the potential to be improved by treatment [25]. Recent data also support its use in men [26].

Yet another new therapeutic approach for constipation involves stimulation of the epithelial guanylate cyclase-C (GC-C) receptor on intestinal epithelial cells. Linaclotide, a non-absorbed substance approved for the treatment of constipation and irritable bowel syndrome with constipation (IBS-C), acts by binding to this specific receptor. An intracellular cascade of events leads to activation of chloride secretion and thereby a net movement of water into the gut lumen, resulting in softer stool and more frequent bowel movements [27]. A feature of particular interest relates to reductions in constipation associated abdominal pain [28] and bloating [29], which can develop gradually over months from the start of treatment. 
Finally, cholinesterase inhibition with oral pyridostigmine has been shown to accelerate colonic transit and improve bowel function in specifically diabetic patients with chronic constipation [30]. Data from this study need to be confirmed in larger trials before conclusive recommendations can be made.

\section{Diarrhoea}

There are a number of factors that might result in a severe situation of chronic diarrhoea in the diabetic gut. The possibility of comorbidities such as coeliac disease, microscopic colitis and side effects of medications-metformin being the most common - must not be forgotten. This minireview is limited to comments related to gut dysmotility and the possibility of small intestinal bacterial overgrowth (SIBO). In general, loperamide is an effective and safe pharmacological treatment for chronic diarrhoea where this is functional in origin [31] or secondary to a diabetic visceral neuropathy. Of the two types of SIBO, the most frequent type occurs in the elderly as a result of reduced stomach acid secretion (medications or atrophic gastritis) and is associated with increased numbers of oropharyngeal flora with few symptoms. The other type of SIBO, and the one pertinent to this mini-review, occurs secondary to GI dysmotility, resulting in colonic flora overgrowth. In diabetic patients with suspected SIBO, formal attempts to objectively demonstrate signs of SIBO are recommended, either by culture from jejunal aspirate or by an indirect method such as a glucose or lactulose breath test. Attempts to treat most often involve combinations of antibiotics effective against both anaerobic and aerobic bacterial strains intermittently for 10-14 days at a time.

\section{Abdominal pain}

The most feared and an often maltreated symptom of autonomic neuropathy is abdominal pain. In order to understand the rationale for using centrally targeted pharmacotherapy, a basic knowledge of the ascending and descending visceral pain pathways and the sequence of events involved in the evolution of chronic abdominal pain is fundamental. In a somatic illness such as diabetes, which can involve neurodegeneration, individual predisposing factors, such as genetic mechanisms, environmental exposures, early trauma, abuse, can result in a highly variable pain situation, particularly if perpetuating factors such as anxiety and depression are not recognised and treated [32]. Wrongful use of analgesics with opioid effects may contribute to the evolution of a pain situation that is very difficult to treat- the narcotic bowel syndrome [33].

Instead, neuropathic pain might be better controlled by some classes of antidepressant medications and patient education about pain mechanisms (Fig. 1). Experience from the treatment of depression and from animal models indicates that pharmacotherapy with antidepressants has the potential to promote a neuroplastic, regenerative situation $[34,35]$ that might be beneficial for the treatment of both the neuropathy itself and comorbid anxiety and depression [36].

Many doctors are confident prescribing low-dose tricyclic antidepressants (TCAs) for the treatment of chronic pain, but also selective serotonin reuptake inhibitors (SSRIs) and selective serotonin-noradrenaline reuptake inhibitors (SNRIs) are useful depending on the clinical situation. If the patient has comorbid anxiety or depression, treatment with an SSRI or SNRI at a dosage equal to that recommended for psychiatric indications would be appropriate. SSRIs probably

\section{Treatment pyramid for abdominal pain}

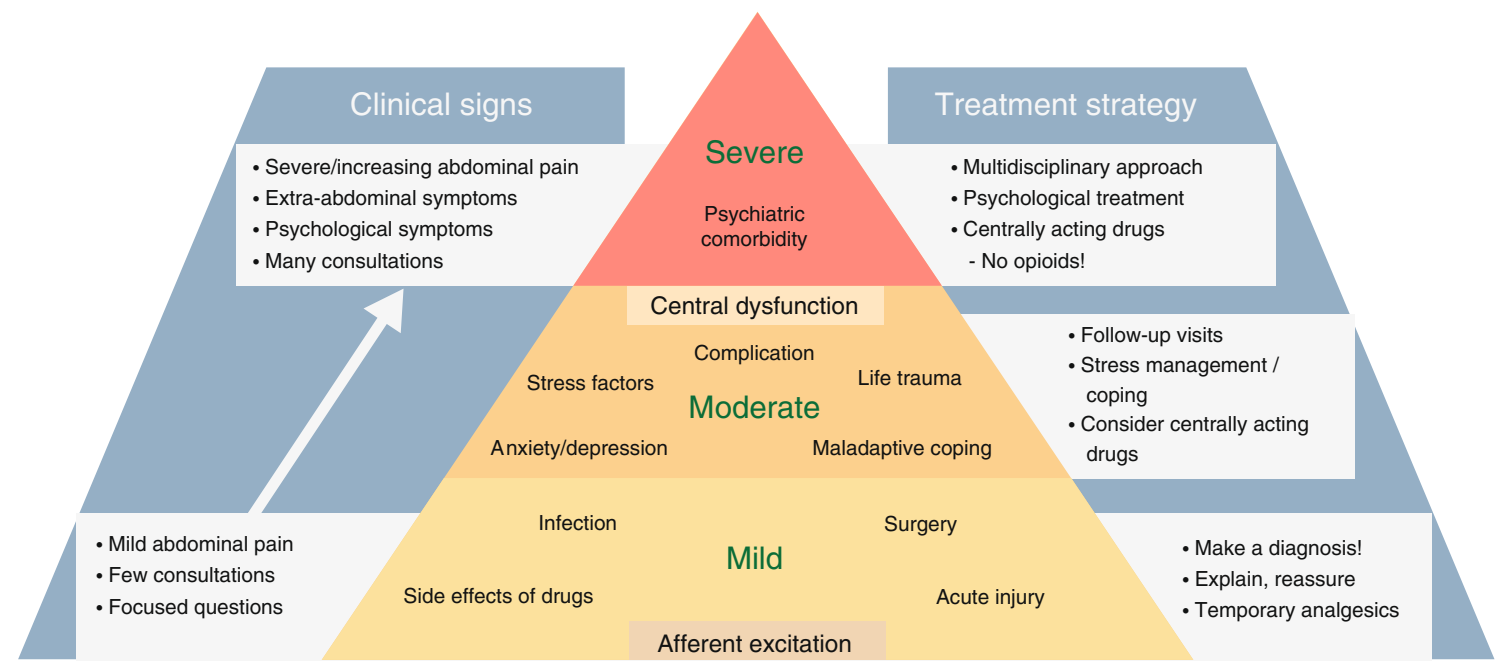

Fig. 1 Conceptual model of the treatment of long-standing abdominal pain 
have the fewest associated side effects, but SNRIs have the advantage of a formal indication for the treatment of peripheral diabetic neuropathic pain [37].

\section{Concluding remark}

Treating gastrointestinal autonomic neuropathy is a challenge. In diabetes, metabolic control is, and will continue to be, the most important therapeutic aim in order to decrease the risk for the development of GI complications and to reduce the acute effects of hyperglycaemia on GI function. However, increasing insights into the role of specific mechanisms involved in the neural control of intestinal motility and gutbrain communication have the potential to result in new therapeutic options targeting specific mechanisms beyond those exploited by current treatments.

Duality of interest The author declares that there is no duality of interest associated with this manuscript.

Contribution statement The author was the sole contributor to this paper.

\section{References}

1. Lovell RM, Ford AC (2012) Global prevalence of and risk factors for irritable bowel syndrome: a meta-analysis. Clin Gastroenterol Hepatol 10:712-721.e4

2. Bytzer P, Talley NJ, Leemon M, Young LJ, Jones MP, Horowitz M (2001) Prevalence of gastrointestinal symptoms associated with diabetes mellitus: a population-based survey of 15,000 adults. Arch Intern Med 161:1989-1996

3. Pasricha PJ, Colvin R, Yates K et al (2011) Characteristics of patients with chronic unexplained nausea and vomiting and normal gastric emptying. Clin Gastroenterol Hepatol 9:567-576.e1-4

4. Abrahamsson $\mathrm{H}$ (2007) Treatment options for patients with severe gastroparesis. Gut 56:877-883

5. Parkman HP, Yates KP, Hasler WL et al (2011) Dietary intake and nutritional deficiencies in patients with diabetic or idiopathic gastroparesis. Gastroenterology 141:486-498, 498.e1-7

6. Olausson EA, Storsrud S, Grundin H, Isaksson M, Attvall S, Simren M (2014) A small particle size diet reduces upper gastrointestinal symptoms in patients with diabetic gastroparesis: a randomized controlled trial. Am J Gastroenterol 109:375-385

7. Parkman HP, Hasler WL, Fisher RS, American Gastroenterological Association (2004) American Gastroenterological Association technical review on the diagnosis and treatment of gastroparesis. Gastroenterology 127:1592-1622

8. Janssen P, Harris MS, Jones M et al (2013) The relation between symptom improvement and gastric emptying in the treatment of diabetic and idiopathic gastroparesis. Am J Gastroenterol 108: 1382-1391

9. Snape WJ Jr, Battle WM, Schwartz SS, Braunstein SN, Goldstein HA, Alavi A (1982) Metoclopramide to treat gastroparesis due to diabetes mellitus: a double-blind, controlled trial. Ann Intern Med 96:444-446

10. McCallum RW, Ricci DA, Rakatansky H et al (1983) A multicenter placebo-controlled clinical trial of oral metoclopramide in diabetic gastroparesis. Diabetes Care 6:463-467

11. Ricci DA, Saltzman MB, Meyer C, Callachan C, McCallum RW (1985) Effect of metoclopramide in diabetic gastroparesis. J Clin Gastroenterol 7:25-32

12. Perkel MS, Moore C, Hersh T, Davidson ED (1979) Metoclopramide therapy in patients with delayed gastric emptying: a randomized, double-blind study. Dig Dis Sci 24:662-666

13. Patterson D, Abell T, Rothstein R, Koch K, Barnett J (1999) A double-blind multicenter comparison of domperidone and metoclopramide in the treatment of diabetic patients with symptoms of gastroparesis. Am J Gastroenterol 94:1230-1234

14. Janssens J, Peeters TL, Vantrappen G et al (1990) Improvement of gastric emptying in diabetic gastroparesis by erythromycin. Preliminary studies. N Engl J Med 322:1028-1031

15. Erbas T, Varoglu E, Erbas B, Tastekin G, Akalin S (1993) Comparison of metoclopramide and erythromycin in the treatment of diabetic gastroparesis. Diabetes Care 16:1511-1514

16. Tack J, Vanormelingen C (2014) Management of gastroparesis: beyond basics. Curr Treat Options Gastroenterol 12:468-477

17. Abell T, McCallum R, Hocking M et al (2003) Gastric electrical stimulation for medically refractory gastroparesis. Gastroenterology 125:421-428

18. Abell TL, Van Cutsem E, Abrahamsson H et al (2002) Gastric electrical stimulation in intractable symptomatic gastroparesis. Digestion 66:204-212

19. McCallum RW, Snape W, Brody F, Wo J, Parkman HP, Nowak T (2010) Gastric electrical stimulation with Enterra therapy improves symptoms from diabetic gastroparesis in a prospective study. Clin Gastroenterol Hepatol 8:947-954

20. McCallum RW, Lin Z, Forster J, Roeser K, Hou Q, Sarosiek I (2011) Gastric electrical stimulation improves outcomes of patients with gastroparesis for up to 10 years. Clin Gastroenterol Hepatol 9: 314-319.e1

21. Ford AC, Suares NC (2011) Effect of laxatives and pharmacological therapies in chronic idiopathic constipation: systematic review and meta-analysis. Gut 60:209-218

22. Tack J, van Outryve M, Beyens G, Kerstens R, Vandeplassche L (2009) Prucalopride (Resolor) in the treatment of severe chronic constipation in patients dissatisfied with laxatives. Gut 58:357-365

23. Camilleri M, Kerstens R, Rykx A, Vandeplassche L (2008) A placebo-controlled trial of prucalopride for severe chronic constipation. N Engl J Med 358:2344-2354

24. Quigley EM, Vandeplassche L, Kerstens R, Ausma J (2009) Clinical trial: the efficacy, impact on quality of life, and safety and tolerability of prucalopride in severe chronic constipation-a 12-week, randomized, double-blind, placebo-controlled study. Aliment Pharmacol Ther 29:315-328

25. Tack J, Stanghellini V, Dubois D, Joseph A, Vandeplassche L, Kerstens R (2014) Effect of prucalopride on symptoms of chronic constipation. Neurogastroenterol Motil 26:21-27

26. Yiannakou Y, Piessevaux H, Bouchoucha $M$ et al (2015) A randomized, double-blind, placebo-controlled, phase 3 trial to evaluate the efficacy, safety, and tolerability of prucalopride in men with chronic constipation. Am J Gastroenterol 110:741-748

27. Lembo AJ, Kurtz CB, Macdougall JE et al (2010) Efficacy of linaclotide for patients with chronic constipation. Gastroenterology 138:886-895.e1

28. Chey WD, Lembo AJ, Lavins BJ et al (2012) Linaclotide for irritable bowel syndrome with constipation: a 26-week, randomized, double-blind, placebo-controlled trial to evaluate efficacy and safety. Am J Gastroenterol 107:1702-1712 
29. Lacy BE, Schey R, Shiff SJ et al (2015) Linaclotide in chronic idiopathic constipation patients with moderate to severe abdominal bloating: a randomized, controlled trial. PLoS One 10:e0134349

30. Bharucha AE, Low P, Camilleri M et al (2013) A randomised controlled study of the effect of cholinesterase inhibition on colon function in patients with diabetes mellitus and constipation. Gut 62:708-715

31. Lavo B, Stenstam M, Nielsen AL (1987) Loperamide in treatment of irritable bowel syndrome - a double-blind placebo controlled study. Scand J Gastroenterol Suppl 130:77-80

32. Tornblom H, Drossman DA (2015) Centrally targeted pharmacotherapy for chronic abdominal pain. Neurogastroenterol Motil 27: 455-467

33. Kurlander JE, Drossman DA (2014) Diagnosis and treatment of narcotic bowel syndrome. Nat Rev Gastroenterol Hepatol 11:410 418
34. Brunoni AR, Lopes M, Fregni F (2008) A systematic review and meta-analysis of clinical studies on major depression and BDNF levels: implications for the role of neuroplasticity in depression. Int J Neuropsychopharmacol 11:1169-1180

35. Han X, Tong J, Zhang J et al (2011) Imipramine treatment improves cognitive outcome associated with enhanced hippocampal neurogenesis after traumatic brain injury in mice. $J$ Neurotrauma 28:995-1007

36. Drossman DA (2009) Beyond tricyclics: new ideas for treating patients with painful and refractory functional gastrointestinal symptoms. Am J Gastroenterol 104:2897-2902

37. Lunn MP, Hughes RA, Wiffen PJ (2014) Duloxetine for treating painful neuropathy, chronic pain or fibromyalgia. Cochrane Database Syst Rev, Issue 1, Art. No.: CD003287. doi:10.1002/ 14651858.CD003287.pub4 